\title{
Can postoperative mean transprosthetic pressure gradient predict survival after aortic valve replacement?
}

\author{
Bart M. Koene - Mohamed A. Soliman Hamad - Wobbe Bouma • \\ Massimo A. Mariani · Kathinka C. Peels · Jan-Melle van Dantzig • \\ Albert H. van Straten
}

Received: 24 August 2013/Accepted: 2 October 2013/Published online: 18 October 2013

(C) The Author(s) 2013. This article is published with open access at Springerlink.com

\begin{abstract}
Background In this study, we sought to determine the effect of the mean transprosthetic pressure gradient (TPG), measured at 6 weeks after aortic valve replacement (AVR) or AVR with coronary artery bypass grafting (CABG) on late all-cause mortality.

Methods Between January 1998 and March 2012, 2,276 patients (mean age $68 \pm 11$ years) underwent TPG analysis at 6 weeks after AVR $(n=1,318)$ or AVR with CABG $(n=958)$ at a single institution. Mean TPG was $11.6 \pm 7.8 \mathrm{mmHg}$ and median TPG $11 \mathrm{mmHg}$. Based on
\end{abstract}

B. M. Koene - M. A. Soliman Hamad · A. H. van Straten Department of Cardiothoracic Surgery, Catharina Hospital, Michelangelolaan 2, Postbus 1350, 5602 ZA Eindhoven,

The Netherlands

e-mail: aasmsn@cze.nl

A. H. van Straten

e-mail: bart.v.straten@cze.nl

B. M. Koene $(\square) \cdot$ W. Bouma $\cdot$ M. A. Mariani

Department of Cardiothoracic Surgery, University Medical

Center Groningen, Hanzeplein 1, Postbus 30.001,

9700 RB Groningen, The Netherlands

e-mail: b.m.j.a.koene@umcg.nl

W. Bouma

e-mail: w.bouma@umcg.nl

M. A. Mariani

e-mail: m.mariani@umcg.nl

K. C. Peels · J.-M. van Dantzig

Department of Cardiology, Catharina Hospital,

Michelangelolaan 2, Postbus 1350, 5602 ZA Eindhoven,

The Netherlands

e-mail: peelscard@me.com

J.-M. van Dantzig

e-mail: jan-melle.v.dantzig@cze.nl the TPG, the patients were split into three groups: patients with a low TPG $(<10 \mathrm{mmHg})$, patients with a medium TPG (10-19 mmHg) and patients with a high TPG $(\geq 20 \mathrm{mmHg}$ ). Cox proportional-hazard regression analysis was used to determine univariate predictors and multivariate independent predictors of late mortality.

Results Overall survival for the entire group at 1, 3, 5, and 10 years was 97, 93, 87 and $67 \%$, respectively. There was no significant difference in long-term survival between patients with a low, medium or high TPG $(p=0.258)$. Independent predictors of late mortality included age, diabetes, peripheral vascular disease, renal dysfunction, chronic obstructive pulmonary disease, a history of a cerebrovascular accident and cardiopulmonary bypass time. Prosthesis-patient mismatch (PPM), severe PPM and TPG measured at 6 weeks postoperatively were not significantly associated with late mortality.

Conclusions TPG measured at 6 weeks after AVR or AVR with CABG is not an independent predictor of allcause late mortality and there is no significant difference in long-term survival between patients with a low, medium or high TPG.

Keywords Prosthesis - Mismatch - Aortic valve · Replacement · Gradient · Survival analysis

$\begin{array}{ll}\text { Abbreviations } \\ \text { AVR } & \text { Aortic valve replacement } \\ \text { BMI } & \text { Body mass index } \\ \text { BSA } & \text { Body surface area } \\ \text { CABG } & \text { Coronary artery bypass grafting } \\ \text { CI } & \text { Confidence interval } \\ \text { COPD } & \text { Chronic obstructive pulmonary disease } \\ \text { CPB } & \text { Cardiopulmonary bypass } \\ \text { CVA } & \text { Cerebrovascular accident }\end{array}$




$\begin{array}{ll}\text { EF } & \text { Ejection fraction } \\ \text { EOA (I) } & \text { Effective orifice area (index) } \\ \text { HR } & \text { Hazard ratio } \\ \text { LV } & \text { Left ventricle } \\ \text { PPM } & \text { Prosthesis-patient mismatch } \\ \text { TEE } & \text { Transesophageal echocardiography } \\ \text { TTE } & \text { Transthoracic echocardiography }\end{array}$

\section{Background}

Implantation of a prosthetic aortic valve too small for the patient's body size could lead to an increased hemodynamic burden by creating left ventricular outflow obstruction, resulting in a higher mean transprosthetic pressure gradient (TPG). This condition after aortic valve replacement (AVR) is known as prosthesis-patient mismatch (PPM) and occurs when the effective orifice area (EOA) of the implanted valve prosthesis is too small in relation to the body surface area (BSA) of the patient $[1,2]$. PPM is expressed by the indexed EOA (EOAI). The EOAI is calculated by dividing the corresponding EOA of each valve type and size by each patient's BSA. Although different cut-off values exist to define PPM, usually a cut-off value of EOAI $\leq 0.85 \mathrm{~cm}^{2} / \mathrm{m}^{2}$ is chosen, as described by Pibarot and colleagues [1]. An EOAI $<0.65 \mathrm{~cm}^{2} / \mathrm{m}^{2}$ is regarded as severe PPM [1, 3, 4]. The EOAI has been shown to negatively correlate with the TPG [5-7] and other studies have shown that despite normal prosthesis function, relatively high TPG can be measured after AVR [3, 4, 8-12].

Studies examining the impact of an undersized prosthetic aortic valve on long-term survival mainly focus on describing the existence of PPM. The impact of PPM on mortality after AVR is still a controversial topic. Several studies have shown that PPM is associated with increased short-term and/or long-term mortality after AVR [13-16]. Other studies contradict these findings and report that PPM does not have a significant impact on survival [17-24].

In this study we focussed on the main hemodynamic consequence of PPM, and we sought to determine the effect of a higher TPG, measured at 6 weeks after AVR or AVR with coronary artery bypass grafting (AVR with CABG), on late all-cause mortality.

\section{Methods}

\section{Study design}

This is a retrospective, observational study on consecutive patients. Data were obtained from the Institutional database, normally utilized for patient care. Clinical data, echocardiographic data, catheterization data, and surgical reports were entered into the institutional database prospectively and analyzed retrospectively. Because anonymous standard clinical follow-up check-ups were used to collect and analyze data, the study was approved by the Medical Ethical Committee.

\section{Patients}

Between January 1998 and March 2012, 2,957 patients underwent AVR $(n=1,701)$ or AVR with CABG $(n=1,256)$ using a mechanical or stented biological aortic valve prosthesis at our institution. Only patients who underwent transthoracic echocardiography (TTE) at 6 weeks after AVR or AVR with CABG were analyzed, leading to the exclusion of 681 patients, including 57 patients who died within 6 weeks postoperatively (early mortality $<6$ weeks $=1.9 \%$ ). Twelve patients were lost to follow-up and were also excluded from our analysis.

Based on the TPG the patients were split into three groups: patients with a low TPG $(<10 \mathrm{mmHg}), n=876$; patients with a medium TPG (10-19 $\mathrm{mmHg}), n=1,184$; and patients with a high TPG $(\geq 20 \mathrm{mmHg}), n=204$. Patient characteristics are summarized in Table 1.

\section{Surgical technique}

All patients underwent surgery using a standard technique. After a median sternotomy, the ascending aorta and right atrium were cannulated and normothermic extracorporeal circulation with non-pulsatile flow was instituted. Myocardial protection was obtained using cold crystalloid cardioplegia (St. Thomas solution) or warm blood cardioplegia according to the surgeon's preference. Cardioplegia was administered in an antegrade fashion through the aortic root and/or selectively in both coronary ostia to induce and maintain cardiac arrest. Retrograde administration of cardioplegia was not used. Concomitant myocardial revascularization was performed in 958 patients. Implantation of the biggest valve possible and using prosthetic valves with optimal hemodynamic profiles in patients with small annular size were strategies used to minimize the incidence of PPM. No aortic annulus enlargement techniques were used. An overview of implanted prosthetic valve types is shown in Table 2 .

Prosthesis-patient mismatch (PPM)

PPM was expressed by the EOAI. The EOAI was calculated by dividing the corresponding EOA of each valve type and size (registered in vitro values published by each manufacturer) by each patient's BSA $[1,6]$. PPM was defined as EOAI $\leq 0.85 \mathrm{~cm}^{2} / \mathrm{m}^{2}$ and severe PPM as EOAI 
Table 1 Characteristics for each pressure gradient group $(n=2,264)$

\begin{tabular}{|c|c|c|c|c|}
\hline Variable & $\begin{array}{l}\text { Low gradient } \\
(<10 \mathrm{mmHg}) n=876\end{array}$ & $\begin{array}{l}\text { Moderate gradient } \\
(10-19 \mathrm{mmHg}) n=1,184\end{array}$ & $\begin{array}{l}\text { High gradient } \\
(\geq 20 \mathrm{mmHg}) n=204\end{array}$ & $p$ \\
\hline Age (years) & $70 \pm 10$ & $67 \pm 11$ & $65 \pm 12$ & $<0.001$ \\
\hline \multicolumn{5}{|l|}{ Sex } \\
\hline Female & $328(37.4)$ & $448(37.8)$ & $56(27.5)$ & 0.015 \\
\hline Endocarditis & $27(3.1)$ & $54(4.6)$ & $14(6.9)$ & 0.035 \\
\hline \multicolumn{5}{|l|}{ Preoperative LV function } \\
\hline Severely impaired $(\mathrm{EF}<30 \%)$ & $39(4.5)$ & $27(2.3)$ & $4(2.0)$ & 0.012 \\
\hline Hypertension & $406(46.3)$ & $549(46.4)$ & $78(38.2)$ & 0.085 \\
\hline Diabetes mellitus & $151(17.2)$ & $203(17.1)$ & $33(16.2)$ & 0.934 \\
\hline Body weight (kg) & $77 \pm 13$ & $79 \pm 14$ & $81 \pm 16$ & $<0.001$ \\
\hline Height $(\mathrm{cm})$ & $170 \pm 9$ & $170 \pm 9$ & $171 \pm 9$ & 0.172 \\
\hline Body surface area, BSA $\left(\mathrm{m}^{2}\right)$ & $1.88 \pm 0.19$ & $1.91 \pm 0.19$ & $1.92 \pm 0.21$ & 0.002 \\
\hline Body mass index, BMI $\left(\mathrm{kg} / \mathrm{m}^{2}\right)$ & $26.8 \pm 4.0$ & $27.4 \pm 4.2$ & $27.5 \pm 4.7$ & 0.006 \\
\hline Peripheral vascular disease (PVD) & $108(12.3)$ & $111(9.4)$ & $20(9.8)$ & 0.091 \\
\hline Renal dysfunction & $46(5.3)$ & $65(5.5)$ & $11(5.4)$ & 0.972 \\
\hline Chronic obstructive pulmonary disease (COPD) & $144(16.4)$ & $194(16.4)$ & $41(20.1)$ & 0.404 \\
\hline Cerebrovascular accident (CVA) & $36(4.1)$ & $64(5.4)$ & $12(5.9)$ & 0.305 \\
\hline Previous cardiac surgery & $64(7.3)$ & $85(7.2)$ & $31(15.2)$ & $<0.001$ \\
\hline Additive EuroSCORE & $6.2 \pm 2.5$ & $5.9 \pm 2.5$ & $5.8 \pm 2.5$ & 0.052 \\
\hline Logistic EuroSCORE & $7.93 \pm 8.33$ & $7.06 \pm 7.06$ & $7.18 \pm 7.69$ & 0.075 \\
\hline \multicolumn{5}{|l|}{ Prosthetic valve diameter, $\mathrm{mm}$} \\
\hline Median & 23 & 23 & 23 & \\
\hline \multicolumn{5}{|l|}{ Prosthetic valve type } \\
\hline Mechanical & $367(41.9)$ & $580(52.3)$ & $120(58.8)$ & $<0.001$ \\
\hline Concomitant coronary artery bypass grafting & $424(48.4)$ & $464(39.2)$ & $66(32.4)$ & $<0.001$ \\
\hline Cardiopulmonary bypass time (min) & $95 \pm 37$ & $91 \pm 36$ & $93 \pm 32$ & 0.024 \\
\hline Aortic cross-clamp time (min) & $70 \pm 26$ & $68 \pm 25$ & $68 \pm 22$ & 0.147 \\
\hline Effective orifice area (EOA) $\left(\mathrm{cm}^{2}\right)$ & $2.16 \pm 0.48$ & $2.06 \pm 0.42$ & $1.94 \pm 0.40$ & $<0.001$ \\
\hline Indexed effective orifice area (EOAI) $\left(\mathrm{cm}^{2} / \mathrm{m}^{2}\right)$ & $1.15 \pm 0.24$ & $1.08 \pm 0.21$ & $1.01 \pm 0.21$ & $<0.001$ \\
\hline PPM $\left(\right.$ EOAI $\left.\leq 0.85 \mathrm{~cm}^{2} / \mathrm{m}^{2}\right)$ & $43(4.9)$ & $145(12.2)$ & $51(25.0)$ & $<0.001$ \\
\hline Severe PPM $\left(\right.$ EOAI $\left.<0.65 \mathrm{~cm}^{2} / \mathrm{m}^{2}\right)$ & $2(0.2)$ & $2(0.2)$ & $3(1.5)$ & 0.007 \\
\hline Mean transprosthetic gradient, TPG $(\mathrm{mmHg})$ & $6 \pm 3$ & $13 \pm 3$ & $28 \pm 11$ & $<0.001$ \\
\hline Mean follow-up (years) & $5.1 \pm 3.5$ & $5.7 \pm 3.5$ & $5.5 \pm 3.5$ & $<0.001$ \\
\hline
\end{tabular}

Data are presented as mean \pm standard deviation or number $(\%)$

$E F$ ejection fraction, $L V$ left ventricular, $P P M$ prosthesis-patient mismatch

$<0.65 \mathrm{~cm}^{2} / \mathrm{m}^{2}[1,3,4]$. There was no significant difference in the prevalence of PPM between patients who died within 6 weeks postoperatively $(n=57)$ and the final study population $(n=2,264)$ (10.5 vs $10.6 \%$, respectively; $p=0.994)$. There were no cases of severe PPM within the early deaths.

\section{Echocardiographic follow-up}

All patients underwent postoperative transthoracic echocardiography (TTE) evaluation of the mean aortic valve pressure gradient 6 weeks after surgery. Mean pressure gradients were calculated using the modified Bernoulli equation with correction for subvalvular velocities. Two cardiologists, who have a long experience in echocardiography, supervised these measurements.

Follow-up and late mortality

Follow-up data concerning mortality were gathered using the databases of the civil registry. The remaining data that could not be retrieved from these databases were obtained by contacting patients' general practitioners. Twelve patients were lost to follow-up; mean follow-up was 
Table 2 Prosthetic valve distribution $(n=2,264)$

\begin{tabular}{ll}
\hline Variable & Value \\
\hline Prosthetic valve diameter (mm) & $23 \mathrm{~mm}$ \\
Median & \\
Prosthetic valve type & $1,067(47.1)$ \\
Mechanical & $577(25.5)$ \\
St. Jude Medical Standard & $377(16.7)$ \\
ATS & $77(3.4)$ \\
St. Jude Medical Regent & $36(1.6)$ \\
St. Jude Medical HP & $1,197(52.9)$ \\
Biological (stented) & $142(6.3)$ \\
Carpentier-Edwards Magna & $412(18.2)$ \\
Carpentier-Edwards Perimount & $291(12.9)$ \\
Sorin Mitroflow & $98(4.3)$ \\
Medtronic Mosaic & $87(3.8)$ \\
St. Jude Trifecta & $167(7.4)$ \\
St. Jude Medical Epic &
\end{tabular}

Data are number of patients (\%)

$5.5 \pm 3.5$ years (range 0.1-14.7 years). Patients lost to follow-up were excluded from our analysis. Late mortality was defined as all-cause death occurring later than 6 weeks after surgery.

\section{Statistics}

Continuous variables were expressed as mean $\pm \mathrm{SD}$. Categorical variables were expressed as percentages. Mean values were compared by using one-way ANOVA or its non-parametric alternative, the Kruskal-Wallis test, for continuous variables and Pearson's Chi-squared test for categorical variables.

Cumulative probability values of survival were estimated with Kaplan-Meier method and compared between groups using log-rank test.

Cox proportional-hazard regression analysis was used to determine univariate predictors and multivariate independent predictors of late mortality. Hazard ratios (HR) were reported with $95 \%$ confidence intervals (CI). Variables considered as potential predictors for multivariable modeling were selected by univariate analyses $(p<0.05)$ and were subsequently selected by stepwise forward selection, with entry and retention in the model set at a significance level of 0.05 . Goodness of fit of the final model was assessed with the Chi-squared goodnessof-fit test.

All calculations were performed using a commercially available statistical package (SPSS 20.0; SPSS Inc., Chicago, IL). Statistically significant differences were established at $p<0.050$.

\section{Results}

Characteristics of the patient population

Patient characteristics are shown in Table 1. There were significantly more patients with endocarditis, a higher body weight, a higher BSA and BMI, a mechanical valve, male gender, previous cardiac surgery and a higher rate of PPM and severe PPM in the high gradient group. Patients in the high gradient group had a significantly lower age, EOA and EOAI. The low-gradient group had significantly more patients with a severely impaired LV function and more patients undergoing concomitant CABG. There were no significant differences between the three groups in other comorbidities, such as hypertension, diabetes, PVD, renal dysfunction, COPD and history of CVA. There was no significant difference in additive or logistic EuroSCORES between the groups.

Long-term survival

Mean follow-up was 5.5 years (range 0.1-14.7 years). Total follow-up was 12,405 patient-years. Long-term survival for the entire group at $1,3,5$, and 10 years was 97 , 93,87 and $67 \%$, respectively.

Survival at $1,3,5$, and 10 years was $97,92,85,66 \%$, respectively, for the low-gradient group, 98, 94, 99 and $68 \%$, respectively, for the medium gradient group and 95, $92,87,66 \%$, respectively, for the high gradient group.

Figure 1 displays the long-term survival after transthoracic echocardiographic (TTE) evaluation of the TPG, 6 weeks after surgery stratified per gradient group. Difference in survival between the groups was not significant $(p=0.258)$.

\section{Predictors of late mortality}

The results of Cox regression analysis for late mortality are shown in Table 3.

Univariate analysis revealed the following predictors of late mortality: age, severely impaired LV function [25], hypertension, diabetes, PVD, renal dysfunction [25], COPD, history of CVA, the use of a mechanical prosthesis, concomitant CABG, CPB time and aortic cross-clamp time. PPM, severe PPM and TPG as a continuous variable or as categorical variable (gradient group) were not significant predictors of late mortality at univariate analysis.

Multivariate analysis revealed the following independent predictors of late mortality: age, diabetes, PVD, renal dysfunction [26], COPD, history of CVA and CPB time. The use of a mechanical prosthesis, concomitant CABG, aortic cross-clamp time, and TPG were not independent predictors of late mortality at multivariate analysis. 


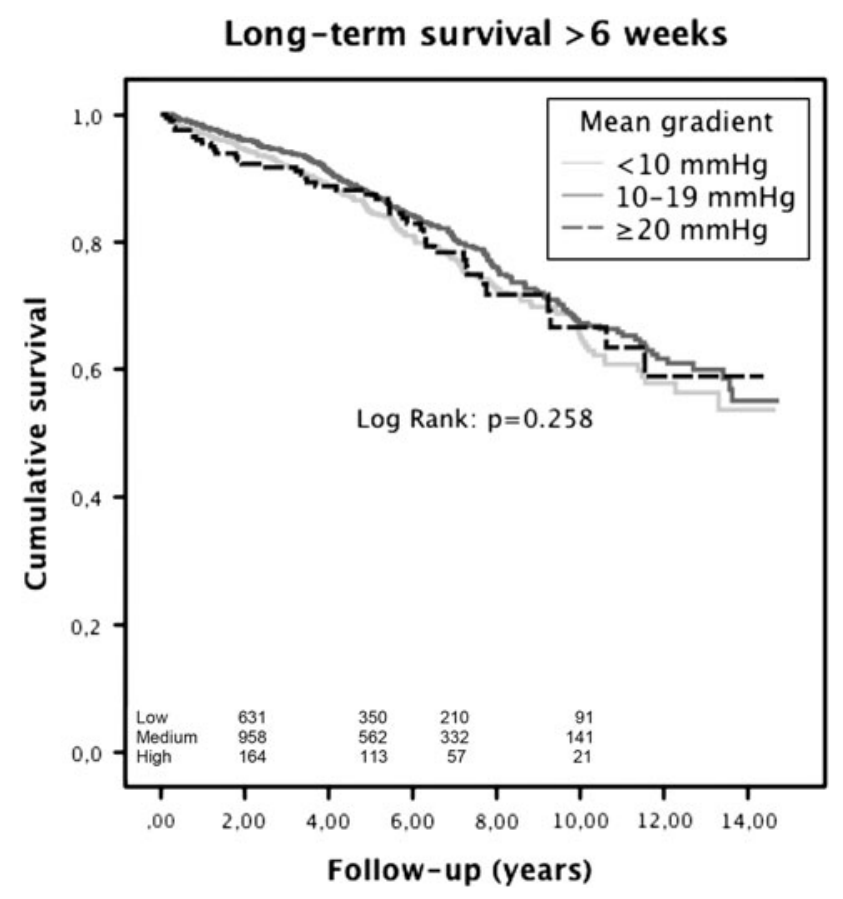

Fig. 1 Long-term survival after transthoracic echocardiographic (TTE) evaluation of the mean transprosthetic pressure gradient (TPG) 6 weeks after surgery stratified per gradient group. Difference in survival between the groups was not significant $(p=0.258)$
Goodness of fit of the final model was assessed with the Chi-squared goodness-of-fit test: $p<0.001$.

\section{Comment}

This study shows that a higher TPG measured at 6 weeks after surgery is not identified as an independent predictor of late mortality after AVR or AVR with CABG. This finding is reassuring when confronted with a postoperative pressure gradient at 6 weeks TTE follow-up.

However, we do not have follow-up data concerning the evolution of the TPG after 6 weeks. In most cases, the gradient measurement at 6 weeks will take place in a stable situation. The TPG measured in this condition will most likely be representative for the future since prostheticrelated factors, such as EOA, hemodynamic profile and surgeon-related factors such as suturing technique and sizing which may play a role in creating a TPG are already defined at that point. The etiology of TPG is complex and multifactorial and patient-related factors such as pannus [27] and thrombus formation may evolve over time. Pannus formation is a bio-reaction to the prosthesis [28-30], usually originating from the ventricular site and its structure
Table 3 Univariate and multivariate Cox analysis of late ( $>6$ weeks) mortality
$C I$ confidence interval, $E F$ ejection fraction, $H R$ hazard ratio, $L V$ left ventricular

${ }^{\text {a }}$ Entered as a continuous variable

b Compared to low-gradient group

${ }^{c}$ Compared to biological valves

\begin{tabular}{|c|c|c|c|c|}
\hline \multirow[t]{2}{*}{ Variable } & \multicolumn{2}{|c|}{ Univariate analysis } & \multicolumn{2}{|c|}{ Multivariate analysis } \\
\hline & $p$ & HR $(95 \%$ CI $)$ & $p$ & $\mathrm{HR}(95 \% \mathrm{CI})$ \\
\hline Age $(\text { years })^{\mathrm{a}}$ & $<0.001$ & $1.07(1.06-1.08)$ & $<0.001$ & $1.06(1.05-1.08)$ \\
\hline Sex (female) & 0.804 & $1.03(0.84-1.25)$ & & \\
\hline Severely impaired LV function $(\mathrm{EF}<30 \%)$ & 0.040 & $1.57(1.02-2.41)$ & 0.062 & $1.51(0.98-2.34)$ \\
\hline Hypertension & 0.003 & $1.33(1.10-1.61)$ & 0.449 & $1.08(0.89-1.31)$ \\
\hline Diabetes mellitus & $<0.001$ & $1.81(1.44-2.29)$ & 0.003 & $1.44(1.13-1.83)$ \\
\hline Endocarditis & 0.115 & $0.62(0.34-1.12)$ & & \\
\hline \multicolumn{5}{|l|}{ Gradient group $^{\mathrm{b}}$} \\
\hline $10-19 \mathrm{mmHg}$ & 0.107 & $0.85(0.69-1.04)$ & 0.781 & $0.97(0.79-1.19)$ \\
\hline$\geq 20 \mathrm{mmHg}$ & 0.815 & $0.96(0.69-1.34)$ & 0.496 & $1.13(0.80-1.59)$ \\
\hline Gradient $^{\mathrm{a}}$ & 0.156 & $0.99(0.98-1.00)$ & & \\
\hline Body mass index, BMI $\left(\mathrm{kg} / \mathrm{m}^{2}\right)$ & 0.535 & $1.01(0.98-1.03)$ & & \\
\hline Peripheral vascular disease (PVD) & $<0.001$ & $2.37(1.84-3.06)$ & $<0.001$ & $1.81(1.40-2.35)$ \\
\hline Renal dysfunction & $<0.001$ & $2.21(1.53-3.18)$ & 0.007 & $1.66(1.15-2.41)$ \\
\hline Chronic obstructive pulmonary disease (COPD) & $<0.001$ & $1.70(1.37-2.12)$ & $<0.001$ & $1.70(1.37-2.13)$ \\
\hline Cerebrovascular accident (CVA) & $<0.001$ & $2.09(1.50-2.92)$ & 0.001 & $1.78(1.27-2.49)$ \\
\hline Mechanical prosthetic valve ${ }^{\mathrm{c}}$ & $<0.001$ & $0.45(0.37-0.55)$ & 0.394 & $0.90(0.70-1.15)$ \\
\hline $\begin{array}{l}\text { Concomitant coronary artery bypass grafting } \\
\text { (CABG) }\end{array}$ & $<0.001$ & $1.56(1.29-1.88)$ & 0.920 & $0.99(0.79-1.24)$ \\
\hline Cardiopulmonary bypass $(\mathrm{CPB})$ time $(\mathrm{min})^{\mathrm{a}}$ & $<0.001$ & $1.01(1.00-1.01)$ & 0.011 & $1.00(1.00-1.01)$ \\
\hline Aortic cross-clamp time $(\mathrm{min})^{\mathrm{a}}$ & $<0.001$ & $1.01(1.00-1.01)$ & 0.495 & $1.00(0.99-1.00)$ \\
\hline $\begin{array}{l}\text { Prosthesis-patient mismatch (PPM) (EOAI } \\
\leq 0.85 \mathrm{~cm}^{2} / \mathrm{m}^{2} \text { ) }\end{array}$ & 0.175 & $1.20(0.92-1.56)$ & & \\
\hline Severe PPM $\left(\right.$ EOAI $\left.<0.65 \mathrm{~cm}^{2} / \mathrm{m}^{2}\right)$ & 0.423 & $1.77(0.44-7.09)$ & & \\
\hline Previous cardiac surgery & 0.151 & $1.29(0.91-1.82)$ & & \\
\hline
\end{tabular}


consists mainly of myofibroblasts and an extracellular matrix such as collagen fiber [31] and thrombus can be a primary cause of pannus formation [32]. On the other hand, a TPG can induce shear stress in the peri-annular tissue, which may also contribute to pannus formation [31]. Although pannus ingrowth can occur in the late postoperative period (mean interval from previous operation $9.6 \pm 2.0$ years reported by Kuniyoshi et al. [33]), valverelated complications due to pannus formation are rare (incidence $0.2-4.5 \%$ per patient year [34]) and scarcely an issue with contemporary mechanical prostheses.

Late mortality is not affected by TPG probably because the gradient measured at 6 weeks after surgery is not likely to increase significantly [35]. Zimmerli et al. [36] found that slight long-term increases in mean pressure gradients are normal findings and do not warrant a change in management strategy if unaccompanied by deterioration of symptoms or clinical signs. Postoperative TPG has to be interpreted differently than the preoperative gradient measured in patients with aortic valve stenosis, which is a progressive disease with increasing gradients over time [37]. In most cases a high TPG will still be a significant reduction in hemodynamic burden for the left ventricle compared to the even higher preoperative aortic valve gradient. This improved and stable situation for the conditioned left ventricle could be another explanation for the lack of influence of TPG on late mortality.

Although there was no significant difference in additive and logistic EuroSCORES [38, 39] and both study populations were homogeneous for most risk factors, some baseline patient characteristics were significantly different between the two groups. Patients in the high gradient group not only had a significantly higher BSA, but also a lower EOA resulting in a higher prevalence of PPM and severe PPM in this group. Nevertheless, PPM and severe PPM were not significant predictors of late mortality and therefore unlikely to have a negative effect on survival in the high gradient group. The fact that PPM does not affect long-term survival is consistent with other studies [7, 19, 24, 40-44].

Most operative characteristics, such as the use of mechanical valve prostheses, concomitant CABG, CPB time, aortic cross-clamp time were significantly different between the groups. Only CPB time was an independent predictor of late mortality whereas aortic cross-clamp time was not. Aortic cross-clamp time is a reflection of the duration of the technical repair, whereas CPB time is a reflexion of the duration of the technical repair time and the time the patient needs to wean from $\mathrm{CPB}$, hence a reflexion of the general condition of the heart.

An important limitation is the retrospective design of this study. Therefore, some baseline patient characteristics were significantly different between the gradient groups. However, there was no significant difference in most comorbidities and EuroSCORES between the groups. Secondly, we focussed on the patients undergoing TTE follow-up at 6 weeks after surgery and the effect of a high TPG on late mortality, thus excluding patients that died before having their TTE follow-up at 6 weeks. The low prevalence of severe PPM ( $n=7,0.3 \%)$, possibly caused by the above-mentioned surgical strategies to avoid PPM, limits the statistical analysis of this group. On the other hand, it is important to note that severe PPM is extremely rare when using straightforward surgical strategies to avoid PPM. In addition, the primary end-point was all-cause mortality. We were not able to retrieve the cause of death that might be equally important and we did not have any information about quality of life after AVR in relation to the TPG. Finally, the relatively short mean follow-up of 5.5 years also limits conclusions about the long-term effect of TPG on survival.

\section{Conclusions}

In conclusion, our findings indicate that TPG measured at 6 weeks after AVR or AVR with CABG is not an independent predictor of all-cause late mortality and there is no significant difference in long-term survival between patients with a low, medium or high TPG.

Acknowledgments We thank Julienne Franssen for language-editing the manuscript.

\section{Conflict of interest None.}

Open Access This article is distributed under the terms of the Creative Commons Attribution License which permits any use, distribution, and reproduction in any medium, provided the original author(s) and the source are credited.

\section{References}

1. Pibarot P, Dumesnil JG (2006) Prosthesis-patient mismatch: definition, clinical impact, and prevention. Heart 92(8):10221029. doi:10.1136/hrt.2005.067363

2. Rahimtoola SH (1978) The problem of valve prosthesis-patient mismatch. Circulation 58(1):20-24

3. Dumesnil JG, Yoganathan AP (1992) Valve prosthesis hemodynamics and the problem of high transprosthetic pressure gradients. Eur J Cardiothorac Surg 6(Suppl 1):S34-S37 (discussion S38)

4. Dumesnil JG, Honos GN, Lemieux M, Beauchemin J (1990) Validation and applications of indexed aortic prosthetic valve areas calculated by Doppler echocardiography. J Am Coll Cardiol 16(3):637-643

5. Pibarot P, Dumesnil JG (2000) Hemodynamic and clinical impact of prosthesis-patient mismatch in the aortic valve position and its 
prevention. J Am Coll Cardiol 36(4):1131-1141 (pii:S07351097(00)00859-7)

6. Tasca G, Brunelli F, Cirillo M, DallaTomba M, Mhagna Z, Troise G, Quaini E (2005) Impact of valve prosthesis-patient mismatch on left ventricular mass regression following aortic valve replacement. Ann Thorac Surg 79(2):505-510. doi:10.1016/j. athoracsur.2004.04.042

7. Cotoni DA, Palac RT, Dacey LJ, O'Rourke DJ (2011) Defining patient-prosthesis mismatch and its effect on survival in patients with impaired ejection fraction. Ann Thorac Surg 91(3):692-699. doi:10.1016/j.athoracsur.2010.11.033

8. Panidis IP, Ross J, Mintz GS (1986) Normal and abnormal prosthetic valve function as assessed by Doppler echocardiography. J Am Coll Cardiol 8(2):317-326

9. Teoh KH, Fulop JC, Weisel RD, Ivanov J, Tong CP, Slattery SA, Rakowski H (1987) Aortic valve replacement with a small prosthesis. Circulation 76(3 Pt 2):III123-III131

10. Teoh KH, Ivanov J, Weisel RD, Daniel LB, Darcel IC, Rakowski H (1990) Clinical and Doppler echocardiographic evaluation of bioprosthetic valve failure after 10 years. Circulation 82(5 Suppl):IV110-IV116

11. van den Brink RB, Verheul HA, Visser CA, Koelemay MJ, Dunning AJ (1992) Value of exercise Doppler echocardiography in patients with prosthetic or bioprosthetic cardiac valves. Am J Cardiol 69(4):367-372

12. Shigenobu M, Sano S (1993) Criteria to select proper valve prosthesis for aortic valve replacement. Comparative assessment of various valve prostheses via continuous wave Doppler echocardiography. J Cardiovasc Surg (Torino) 34(3):203-208

13. Rao V, Jamieson WR, Ivanov J, Armstrong S, David TE (2000) Prosthesis-patient mismatch affects survival after aortic valve replacement. Circulation 102(19 Suppl 3):III5-III9

14. Blais C, Dumesnil JG, Baillot R, Simard S, Doyle D, Pibarot P (2003) Impact of valve prosthesis-patient mismatch on shortterm mortality after aortic valve replacement. Circulation 108(8):983-988. doi:10.1161/01.CIR.0000085167.67105.32

15. Tasca G, Mhagna Z, Perotti S, Centurini PB, Sabatini T, Amaducci A, Brunelli F, Cirillo M, Dalla Tomba M, Quaini E, Troise G, Pibarot P (2006) Impact of prosthesis-patient mismatch on cardiac events and midterm mortality after aortic valve replacement in patients with pure aortic stenosis. Circulation 113(4):570-576. doi:10.1161/CIRCULATIONAHA.105.587022

16. Walther T, Rastan A, Falk V, Lehmann S, Garbade J, Funkat AK, Mohr FW, Gummert JF (2006) Patient prosthesis mismatch affects short- and long-term outcomes after aortic valve replacement. Eur J Cardiothorac Surg 30(1):15-19. doi:10.1016/j. ejcts.2006.04.007

17. Medalion B, Blackstone EH, Lytle BW, White J, Arnold JH, Cosgrove DM (2000) Aortic valve replacement: is valve size important? J Thorac Cardiovasc Surg 119(5):963-974 (pii:S0022522300163834)

18. Frapier JM, Rouviere P, Razcka F, Aymard T, Albat B, Chaptal PA (2002) Influence of patient-prosthesis mismatch on long-term results after aortic valve replacement with a stented bioprosthesis. J Heart Valve Dis 11(4):543-551

19. Flameng W, Meuris B, Herijgers P, Herregods MC (2006) Prosthesis-patient mismatch is not clinically relevant in aortic valve replacement using the Carpentier-Edwards Perimount valve. Ann Thorac Surg 82(2):530-536. doi:10.1016/j.athoracsur. 2006.03.089

20. Moon MR, Pasque MK, Munfakh NA, Melby SJ, Lawton JS, Moazami N, Codd JE, Crabtree TD, Barner HB, Damiano RJ Jr (2006) Prosthesis-patient mismatch after aortic valve replacement: impact of age and body size on late survival. Ann Thorac Surg 81(2):481-488. doi:10.1016/j.athoracsur.2005.07.084 (discussion 489)
21. Monin JL, Monchi M, Kirsch ME, Petit-Eisenmann H, Baleynaud S, Chauvel C, Metz D, Adams C, Quere JP, Gueret P, Tribouilloy C (2007) Low-gradient aortic stenosis: impact of prosthesispatient mismatch on survival. Eur Heart J 28(21):2620-2626. doi:10.1093/eurheartj/ehm393

22. Nozohoor S, Nilsson J, Luhrs C, Roijer A, Sjogren J (2007) The influence of patient-prosthesis mismatch on in-hospital complications and early mortality after aortic valve replacement. J Heart Valve Dis 16(5):475-482

23. Mascherbauer J, Rosenhek R, Fuchs C, Pernicka E, Klaar U, Scholten C, Heger M, Wollenek G, Maurer G, Baumgartner H (2008) Moderate patient-prosthesis mismatch after valve replacement for severe aortic stenosis has no impact on shortterm and long-term mortality. Heart 94(12):1639-1645. doi:10. 1136/hrt.2008.142596

24. Howell NJ, Keogh BE, Barnet V, Bonser RS, Graham TR, Rooney SJ, Wilson IC, Pagano D (2006) Patient-prosthesis mismatch does not affect survival following aortic valve replacement. Eur $\mathrm{J}$ Cardiothorac Surg 30(1):10-14. doi:10.1016/j.ejcts.2006.03.046

25. Zuern CS, Eick C, Rizas K, Stoleriu C, Woernle B, Wildhirt S, Herdeg C, Stock U, Gawaz M, Bauer A (2012) Prognostic value of mild-to-moderate pulmonary hypertension in patients with severe aortic valve stenosis undergoing aortic valve replacement. Clin Res Cardiol 101(2):81-88. doi:10.1007/s00392-011-0367-3

26. Bruch C, Kauling D, Reinecke H, Rothenburger M, Scheld HH, Breithardt G, Wichter T (2007) Prevalence and prognostic impact of comorbidities in patients with severe aortic valve stenosis. Clin Res Cardiol 96(1):23-29. doi:10.1007/s00392-006-0452-1

27. Tiete AR, Sachweh JS, Groetzner J, Gulbins H, Muehler EG, Messmer BJ, Daebritz SH (2006) Systemic mechanical heart valve replacement in children under 16 years of age. Clin Res Cardiol 95(5):281-288. doi:10.1007/s00392-006-0376-9

28. Vitale N, Renzulli A, Agozzino L, Pollice A, Tedesco N, de Luca Tupputi S, Chinosa L, Cotrufo M (1997) Obstruction of mechanical mitral prostheses: analysis of pathologic findings. Ann Thorac Surg 63(4):1101-1106 (pii:S0003497596013914)

29. Ibrahim MF, David TE (2002) Mitral stenosis after mitral valve repair for non-rheumatic mitral regurgitation. Ann Thorac Surg 73(1):34-36

30. Blumenstein J, Van Linden A, Kim WK, Skwara W, Schoenburg M, Arsalan M, Moellmann H, Niederhagen M, Kempfert J, Walther T (2013) Early SAPIEN transcatheter heart valve dysfunction due to tissue ingrowth in an octogenarian. Clin Res Cardiol 102(3):237-240. doi:10.1007/s00392-012-0518-1

31. Teshima H, Hayashida N, Yano H, Nishimi M, Tayama E, Fukunaga S, Akashi H, Kawara T, Aoyagi S (2003) Obstruction of St Jude Medical valves in the aortic position: histology and immunohistochemistry of pannus. J Thorac Cardiovasc Surg 126(2):401-407 (pii:S0022522303007025)

32. Becker RC, Eisenberg P, Turpie AG (2001) Pathobiologic features and prevention of thrombotic complications associated with prosthetic heart valves: fundamental principles and the contribution of platelets and thrombin. Am Heart J 141(6):1025-1037. doi:10.1067/mhj.2001.115492

33. Kuniyoshi Y, Koja K, Miyagi K, Shimoji M, Uezu T, Arakaki K, Yamashiro S, Mabuni K, Senaha S, Nakasone Y (2003) Pannus formation in aortic valve prostheses in the late postoperative period. J Artif Organs 6(3):179-182. doi:10.1007/s10047-003-0226-8

34. Deviri E, Sareli P, Wisenbaugh T, Cronje SL (1991) Obstruction of mechanical heart valve prostheses: clinical aspects and surgical management. J Am Coll Cardiol 17(3):646-650

35. Puls M, Viel T, Danner BC, Jacobshagen C, Teucher N, Hanekop G, Schondube F, Hasenfuss G, Seipelt RG, Schillinger W (2012) The risk-to-benefit ratio of transcatheter aortic valve implantation in specific patient cohorts: a single-centre experience. Clin Res Cardiol 101(7):553-563. doi:10.1007/s00392-012-0426-4 
36. Zimmerli M, Kipfer B, Wagdi P (1997) Long-term Doppler echocardiographic follow up in normally functioning aortic St. Jude Medical prosthesis. J Heart Valve Dis 6(5):531-534

37. Daniel WG, Baumgartner H, Gohlke-Barwolf C, Hanrath P, Horstkotte D, Koch KC, Mugge A, Schafers HJ, Flachskampf FA (2006) Aortic stenosis. Clin Res Cardiol 95(11):620-641. doi:10. 1007/s00392-006-0458-8

38. Gummert JF, Funkat A, Osswald B, Beckmann A, Schiller W, Krian A, Beyersdorf F, Haverich A, Cremer J (2009) EuroSCORE overestimates the risk of cardiac surgery: results from the national registry of the German Society of Thoracic and Cardiovascular Surgery. Clin Res Cardiol 98(6):363-369. doi:10. 1007/s00392-009-0010-8

39. Gulbins H, Malkoc A, Ennker J (2008) Combined cardiac surgical procedures in octogenarians: operative outcome. Clin Res Cardiol 97(3):176-180. doi:10.1007/s00392-007-0615-8

40. Vicchio M, Della Corte A, De Santo LS, De Feo M, Caianiello G, Scardone M, Cotrufo M (2008) Prosthesis-patient mismatch in the elderly: survival, ventricular mass regression, and quality of life. Ann Thorac Surg 86(6):1791-1797. doi:10.1016/j.athoracsur.2008.09. 005
41. Urso S, Sadaba R, Monleon-Getino T, Aldamiz-Echevarria G (2010) Moderate patient-prosthesis mismatch has no independent effect on 30-day mortality after isolated aortic valve replacement. Rev Esp Cardiol 63(4):409-414 (pii:S0300-8932(10)70061-0)

42. Howell NJ, Keogh BE, Ray D, Bonser RS, Graham TR, Mascaro J, Rooney SJ, Wilson IC, Pagano D (2010) Patient-prosthesis mismatch in patients with aortic stenosis undergoing isolated aortic valve replacement does not affect survival. Ann Thorac Surg 89(1):60-64. doi:10.1016/j.athoracsur.2009.07.037

43. Kato Y, Suehiro S, Shibata T, Sasaki Y, Hirai H (2007) Impact of valve prosthesis-patient mismatch on long-term survival and left ventricular mass regression after aortic valve replacement for aortic stenosis. J Card Surg 22(4):314-319. doi:10.1111/j.15408191.2007.00414.x

44. Koene BM, Soliman Hamad MA, Bouma W, Mariani MA, Peels KC, van Dantzig JM, van Straten AH (2013) Impact of prosthesis-patient mismatch on early and late mortality after aortic valve replacement. J Cardiothorac Surg 8(1):96. doi:10.1186/ 1749-8090-8-96 